\title{
Alcohol control policies in low- and middle-income countries: Testing impacts and improving policymaking practice
}

\section{Introduction}

Alcohol is a major contributor to the global burden of disease (Lim et al., 2012), and is a major source of health and social harm in many middle- and low-income countries, as well as in high-income countries. In recognition of this, a Global Strategy to Reduce the Harmful Effects of Alcohol was adopted in 2010 by the World Health Organization's governing body, the World Health Assembly (WHA) (WHO, 2010). Since then, there has also been increasing international recognition of alcohol's role in social problems, including crime, family problems, and lost work productivity: "beyond health consequences," WHO notes, "the harmful use of alcohol brings significant social and economic losses to individuals and society at large" (http://www.who.int/mediacentre/ factsheets/fs349/en/). New emphasis has been put, too, on alcohol's major contribution as a risk factor for noncommunicable diseases (NCDs) such as cancer, heart disease, and liver cirrhosis; WHO's global goals for NCD control include the (somewhat fuzzily defined) goal of a $10 \%$ reduction in the "harmful use of alcohol . . . as appropriate” by 2020 (WHO, 2013). Together, these steps reflect a greater international recognition of alcohol as a major issue to be addressed in improving global health.

From a public health and welfare perspective, these are the positive sides of the situation at the international level. The negative sides are many, and are often sufficient to thwart effective action aimed at reducing rates of alcohol problems. The resources devoted by international agencies to alcohol issues are tiny-no more than a handful of international civil servants are working on alcohol issues (at WHO's headquarters and regional offices), compared to dozens for tobacco and hundreds for substances covered by the drug treaties. WHO has found it extremely difficult to raise extra-budgetary funds for alcohol programs. International nongovernmental organizations with a focus on alcohol are also thin on the ground. Meanwhile, global alcohol producers and governments influenced by them work effectively to minimize international action to limit damage from alcohol. Much of this activity occurs behind closed doors; as Sornpaisarn and Kaewmungkan (2014) note, researchers have no access to internal alcohol industry documents, and can observe only the public side of the industry's public relations, primarily through its Social Aspects Organizations (Room, 2006). Meanwhile, alcohol is treated essentially as an ordinary item of trade by the
World Trade Organization (WTO) and in international trade agreements, so that national restrictions are often overturned in trade disputes (Ziegler, 2009).

For these reasons, many countries are largely on their own in seeking to control their national alcohol markets and limit the damage from drinking. For instance, this was Malawi's situation in 2007, when it accepted a national alcohol policy formulated by an alcohol-industry-funded consultant from Australia (Bakke \& Endal, 2010). Ferreira-Borges et al. (2014) give an encouraging report on later developments in Malawi, which, at the time their article was written, was close to adopting a final version of a new national alcohol policy, following the extensive consultations described by the researchers. Even so, Ferreira-Borges and her colleagues emphasise the "challenge" of managing the influence of stakeholders on the process, noting that "vested interests have accelerated their lobbying and have sought to change the document and slow its progress."

The paper by Sornpaisarn and Kaewmunghun (2014) illustrates vividly the influence that vested industry interests can exert on alcohol policy in a major developing country, although the paper also makes the point that industry interests are not necessarily unified. The extent of industry influence noted in the paper is remarkable, considering that Thailand has a position of considerable leadership in global alcohol policy-for instance, in the WHA; in Thai Health's leading role in WHO's strand of work under the global alcohol strategy on alcohol's harm to others; and in Thailand's announced intention to require graphic warnings on alcohol containers-a move which is being strongly resisted, in WTO technical barriers to trade negotiations, by many high-income alcohol-exporting countries (O’Brien, 2013).

The paper by Tantirangsee et al. (2014) further illustrates the broad scope of Thai research on alcohol, with an interesting analysis of a series of large surveys of schoolchildren. It may be a coincidence that the paper's finding of a decrease in drinking among early teenagers parallels other recent findings in culturally different circumstances (Livingston, 2014). But it is interesting to speculate whether there is something in common behind the shifts. In an era when global panic over the drugs under 
international control appears to be subsiding, there seems to be a growing willingness to recognise that, in fact, alcohol is among the most problematic of psychoactive substances. Through such mechanisms as increased parental concern, it is possible that such a shift in thinking might be showing up widely in the behavior of younger teenagers.

Parry's paper (2014) uses the structure of WHO global alcohol strategy as a matrix for eliciting expert opinions on the status of alcohol policy in South Africa. Informants were asked to give ratings from one to 10 on each of 12 dimensions, with endpoints for each range defined by the investigator, and asked to rate South African policy on each dimension both contemporaneously and five years before. The highest mean contemporaneous rating was 4.59 , while the highest for five years before was 3.16, suggesting, on the one hand, that the informants had a quite critical view of national policies, and on the other, that they perceived there had been some improvement. While the paper proposes the use of this "score card" for comparisons across countries, it acknowledges potential barriers to this, such as the possibility of "variations in the degree to which members of different societies tend to be critical of government policy and implementation.” It remains a question for further study whether the approach this paper takes-using general ratings based on the judgement of experts-will prove more useful cross-nationally than the scores based on specific policy provisions used in previous cross-national comparative ratings.

The paper by Kolosnitsyna et al. (2014) offers an interesting update on alcohol control policies in Russia; as well, it takes advantage of a one-year window in which there was regional control over opening hours to provide an invaluable analysis of the differential effects of variations in restrictions on hours for alcohol sales. The paper finds that greater restrictions, particularly on how late in the evening sales were permitted to continue, did have an effect in lowering alcohol consumption, both of beer and of all alcoholic beverages (mostly spirits), whether measured in official sales statistics or by respondents' self-reports in successive cross-sectional surveys. These strong findings extend into a new sociocultural setting the general findings that the paper notes in the previous research literaturemostly from Nordic countries, North America, Britain and Australia (e.g., Kypri et al., 2014; Rossow \& Norström, 2012) but also including Brazil (Duailibi et al., 2007) — that restricting opening hours, and particularly night opening hours, reduces not only consumption, but also alcoholrelated problems.

Taken together, the papers in this issue make a significant contribution to the knowledge base for alcohol policymaking in low- and middle-income countries. The papers by Kolsnitsyna et al. (2014) and Tantirangsee et al. (2014) contribute to our understanding, essential for informed policymaking, of what strategies work under what circumstances in such countries. While there has been a slow accumulation of such studies (Medina Mora et al., in press; Room et al., 2002), there is an urgent need for much more work of this kind. Also needed is a global clearinghouse, provided through WHO or otherwise, which would be able to advise countries and localities and provide the relevant evidence on public-health-oriented alcohol policy measures and their implementation. In setting priorities for policymaking, countries also need ways of evaluating where they stand on different dimensions of alcohol policymaking, and the paper by Parry (2014) is a contribution in this regard.

The papers by Sornpaisarn and Kaewmungkun (2014) and Ferreira-Borges et al. (2014) are a reminder of the complexity of the actual policymaking process, where interests other than public health and welfare must be taken into account. There is a need to develop a knowledge base in this area as well, building on case studies like these two papers to develop rules of practice for ensuring that proper priority is given to health and welfare interests in the formulation and implementation of alcohol control policies. The results from the comparative risk analyses of the Global Burden of Disease (Rehm et al., 2013) remind us that, in most parts of the world, we still have far to go in minimizing the harmful use of alcohol.

\section{Acknowledgment}

The author's position at the University of Melbourne is funded by the Victorian Department of Health and the Foundation for Alcohol Research and Education (FARE).

\section{References}

Bakke, Ø., \& Endal, D. (2010). Alcohol policies out of context: Drinks industry supplanting government role in sub-Saharan Africa. Addiction, 105, 22-28.

Duailibi, S., Ponicki, W., Grube, J., Pinsky, I., Laranjeiro, R., \& Raw, M. (2007). The effect of restricting opening hours on alcohol-related violence. American Journal of Public Health, 97, 2276-2280.

Ferreira-Borges, C., Endal, D., Babor, T., Dias, S., Kachiwiya, M., \& Zakeyu, N. (2014). Alcohol policy process in Malawi: Making it happen. International Journal of Alcohol \& Drug Research, 3(3), 187-192.

Kolosnitsyna, M., Sitdikov, M., \& Khorkina, N. (2014). Availability restrictions and alcohol consumption: A case of restricted hours of alcohol sales in Russian regions. International Journal of Alcohol \& Drug Research, 3(3), 193-201.

Kypri, K., McElduff, P., \& Miller, P. (2014) Restrictions in pub closing times and lockouts in Newcastle, Australia five years on. Drug and Alcohol Review, 33(3), 323326.

Lim, S. S., Vos, T., Flaxman, A. D., Danaei, G., Shibuya, K., Adair-Rohani, H., . . . Ezzati, M. (2012). A comparative risk assessment of burden of disease and injury attributable to 67 risk factors and risk factor clusters in 21 regions, 1990-2010: A systematic analysis for the Global Burden of Disease Study 2010. The Lancet, 380(9859), 2224-2260.

Livingston, M. (2014). Trends in non-drinking among Australian adolescents. Addiction, 109(6), 922-929. 
Medina Mora, M. E., Monteiro, M., Room, R., Rehm, J., Jernigan, D., Sanchez-Moreno, D., \& Real, T. (in press). Alcohol and alcohol use disorders. In: Patel, V., Chisholm, D., Vos, T., Medina Mora, M. E., Dua, T. (Eds.), Mental, neurological and substance use disorders, Vol. 8 of Disease control priorities in developing countries, 3rd ed. Washington, DC, United States: World Bank.

O’Brien, P. (2013). Australia's double standard on Thailand's alcohol warning labels. Drug and Alcohol Review, 32(1), 5-10.

Parry, C. (2014). Testing the National Alcohol Policy Score Card (NAPSC) to assess progress in implementing a comprehensive policy response to reduce the harmful use of alcohol in South Africa. International Journal of Alcohol \& Drug Research, 3(3), 202-209.

Rehm, J., Borges, G., Gmel, G., Graham, K., Grant, B., Parry, C., . . . Room, R. (2013). The Comparative Risk Assessment for alcohol as part of the Global Burden of Disease 2010 Study: What changed from the last study? International Journal of Alcohol and Drug Research, 2(1), 1-5. http://www.ijadr.org/index.php/ ijadr/article/view/132/95

Room, R. (2006). Advancing industry interests in alcohol policy: The double game. Nordisk Alkohol- \& Narkotikatidskrift, 26, 389-402. http://www.nordicwelfare.org/PageFiles/9945/Advanc ing\%20industry\%20interests\%20in\%20alcohol\%20po licy\%20the\%20double\%20game.pdf

Room, R., Jernigan, D., Carlini-Marlatt, B., Gureje, O., Mäkelä, K., Marshall, M., . . . Saxena, S. (2002). Alcohol and developing societies: A public health approach. Helsinki: Finnish Foundation for Alcohol Studies \& Geneva: World Health Organization. Updated edition in Spanish:

Room, R., Jernigan, D., Carlini, B. H., Gureje, O., Mäkelä, K., Marshall, M., . . . Shield, K. (2013). El alcohol y los países en desarrollo: Una perspectiva de salud pública. Mexico City: Fondo de Cultura Económica \& Organizatión Panamericana de la Salud.

Rossow, I., \& Norström, T. (2012). The impact of small changes in bar closing hours on violence: The Norwegian experience from 18 cities. Addiction, 107, 530-537.

Sornpaisarn, B., \& Kaewmungkun, C. (2014). The politics of the alcohol taxation system in Thailand: The behaviours of three major alcohol companies from 1992 to 2012. International Journal of Alcohol \& Drug Research, 3(3), 210-218.

Tantirangsee, N., Assanangkornchai, S., \& Geater, A. F. (2014) Trends and associated factors of alcohol consumption among Southern Thai adolescents, 20032009. International Journal of Alcohol \& Drug Research, 3(3), 219-225.

WHO (2010). Global strategy to reduce the harmful use of alcohol. Geneva, Switzerland: Author.

WHO (2013). Draft comprehensive global monitoring framework and targets for the prevention and control of noncommunicable diseases. WHA document A66/8. Geneva: Author. http://apps.who.int/gb/ebwha/ pdf_files/WHA66/A66_8-en.pdf?ua=1
Ziegler, D. (2009). The alcohol industry and trade agreements: A preliminary assessment. Addiction, 104(Suppl. 1), 13-26.

\section{Robin Room}

Centre for Alcohol Policy Research, Turning Point, Fitzroy, Victoria, Australia; Melbourne School of Population and Global Health, University of Melbourne, Melbourne; and Centre for Social Research on Alcohol \& Drugs, Stockholm University, Stockholm. 